\title{
ISÓTOPOS DE CARBONO E OXIGÊNIO DOS MÁRMORES ASSOCIADOS COM O DEPÓSITO FÓSFORO URANÍFERO DE ITATAIA, CEARÁ
}

\section{GIVALDO LESSA CASTRO ${ }^{1,2}$, CLOVIS VAZ PARENTE ${ }^{2}$, CÉSAR ULISSES VIEIRA VERÍSSIMO², ALCIDES NÓBREGA SIAL ${ }^{3}$, MARIA DA GLORIA MOTTA GARCIA ${ }^{2}$, ROBERTO VENTURA SANTOS ${ }^{4}$, RAFAEL CASTRO DE MELO $^{2} \&$ ALDINEY ALMEIDA SANTOS ${ }^{2}$}

\begin{abstract}
Resumo A jazida fósforo-uranífera de Itataia é constituída por colofanitos, que aparecem como corpos irregulares, maciços e em veios, junto a corpos lenticulares de mármores e rochas calcissilicáticas intercaladas em rochas metassedimentares pelíticas e psamíticas meso a neoproterozóicas metamorfisadas em fácies anfibolito alto. Corpos pegmatíticos de dimensões centimétricas a métricas com muscovita e turmalina são comuns e seccionam rochas metapelíticas e seus mobilizados anatéticos. Pegmatitos mais enriquecidos em plagioclásio e empobrecidos em filossilicatos cortam diferentes estratos de mármore, alguns dos quais estando mineralizados em colofana. Estruturalmente, as lentes de mármore, principais rochas hospedeiras do minério, mostram uma organização estrutural heterogênea, resultado de importantes dobramentos e cavalgamentos. Estudos isotópicos de $\mathrm{C}$ e $\mathrm{O}$ em carbonatos feitos ao longo de uma das seções que cortam as rochas metacarbonáticas, parcialmente mineralizadas, mostram uma variação de $+2,0 \mathrm{a}-5,0 \%$ nos valores de $\delta^{13} \mathrm{C}_{\mathrm{PDB}}$ e de $+16,3 \mathrm{a}+24,2 \%$ para o $\delta \mathrm{d}^{18} \mathrm{O}_{\mathrm{SMOw}}$. Eventos pós-deposicionais, tais como metamorfismo associado a uma tectônica dúctil e dúctil-frágil acompanhada de infiltração de fluidos hidrotermais e/ou supergênicos e carstificações são responsáveis pelas modificações nas razões isotópicas originais. Os mármores dolomíticos delgados e impuros, que apresentam as menores razões isotópicas, são os mais afetados por esses eventos. Faixas miloníticas retromórficas de espessura métrica e brechas de dissolução cárstica a uma profundidade de $144 \mathrm{~m}$, intercaladas aos estratos metacarbonáticos, poderiam materializar os canais de percolação desses fluidos. As camadas metacarbonáticas mais espessas e com razões $\delta^{13} \mathrm{C}_{\mathrm{PDB}}$ e $\delta^{18} \mathrm{O}_{\mathrm{SMOW}}$ mais altas $\left(\delta^{13} \mathrm{C}_{\mathrm{PDB}} 0 \pm 2 \%\right.$ e $\delta^{18} \mathrm{O}_{\mathrm{SMOW}}$ $>20 \%$ ) retratam os leitos melhor preservados ou menos modificados isotopicamente. Não obstante, a associação mineralogica (diopsídio, escapolita, flogopita, clinocloro e tremolita) indica a existência de reações de devolatização e/ou descarbonatação, o que não elimina, entretanto, a hipótese da interação com fluidos externos como responsável pela variação isotópica observada.
\end{abstract}

Palavras-chave: Domínio Ceará Central, isótopos de carbono e oxigênio, metalogênese, mineralização fósforo-uranífera, NE do Brasil.

\begin{abstract}
CARBON AND OXYGEN ISOTOPES OF MARBLES ASSOCIATED TO THE PHOSPHOROUS-URANIUM DEPOSIT OF ITATAIA - CEARÁ STATE, BRAZIL The phosphorous-uranium deposit of Itataia, Ceará State, NE Brazil, is characterized by colophanites that occur as massive and irregular bodies, and as veins, associated to marbles and calc-silicate lenses that are enclosed in Meso to neoproterozoic pelitic and psamitic metasediments rocks metamorphosed under high amphibolite-facies. Centimetric to metric muscovite- and tourmaline-bearing pegmatitic bodies are common and crosscut both the metapelites and their anatetic products. Plagioclase-rich phyllosilicate-poor pegmatites cut different marble levels, some of which are mineralized in colophane. The marble beds, which are the main ore host-rock, show a heterogeneous structural pattern as a result of complex folding and thrusting. $\mathrm{C}$ and $\mathrm{O}$ isotope analyses in carbonates from one of the sections that crosscut partially mineralized metacarbonatic rocks show $\delta^{13} \mathrm{C}_{\mathrm{PDB}}$ values ranging from $+2,0$ to $-5,0 \%$ and $\delta^{18} \mathrm{O}_{\mathrm{SMOW}}$ values from $+16,3$ to $+24,2 \%$. Changes in the original isotopic ratios are mainly related to regional metamorphism, as well as to ductile and ductile-brittle post-depositional events associated with infiltration of hydrothermal and/or supergenic fluids and karstification. The thin, impure dolomitic marble bodies, which show the lowest isotopic ratios, were the most affected by these events. Retromorphic mylonitic levels and especially karstic dissolution breccias found at depths of $144 \mathrm{~m}$ and inserted in the carbonatic levels are likely to represent fluid percolation channels. The thicker metacarbonatic levels, which show the highest $\delta^{13} \mathrm{C}_{\mathrm{PDB}}$ and $\delta^{18} \mathrm{O}_{\mathrm{SMOw}}$ ratios $(0 \pm 2 \%$ and $>20 \%$, respectively), represent isotopically best-preserved beds. The mineral assemblage (diopside, scapolite, phlogopite, clinochlore and tremolite) indicates that devolatization and/or decarbonation reactions did occur, but this does not preclude the hypothesis of external fluid interaction as responsible for the isotopic variation.
\end{abstract}

Keywords: Carbon isotopes, Ceará State, oxygen isotopes, phosphorous-uranium mineralizations, metallogenesis, NE Brazil

INTRODUÇÃO A aplicação de isótopos estáveis em estudos regionais tem se concentrado na identificação das fontes da fase fluida, nos processos de interação fluido-rocha e na determinação de temperaturas aparentes baseadas em fracionamentos ${ }^{18} \mathrm{O} /{ }^{16} \mathrm{O}$. Os diferentes grupos de rochas e fluidos de diversas origens exi- bem razões isotópicas características e, por esta razão, variações nestes valores podem implicar a existência de troca isotópica com materiais com origem distinta. No caso de rochas carbonáticas, a origem e evolução dos fluidos tem sido alvo de numerosas pesquisas. Estudos isotópicos de oxigênio em rochas calcissilicáticas

\footnotetext{
1 - Depto. de Geologia UFC/INB, Campus Universitário do Pici, Bloco 912, CEP 60455-760, Fortaleza, Ce E-mail:givaldolessa@rapix.com.br

2 - Depto. de Geologia/UFC, Campus Universitário do Pici, Bloco 912, CEP 60455-760, Fortaleza,Ce. E-mail : clovis@ufc.br

3 - NEG-LABISE, Dept ${ }^{\circ}$ de Geologia, UFPE, CP 7852, Cidade Universitária, 50670-000, Recife,PE, E-mail:ans@ufpe.br

4 - Instituto de Geociências/UNB, Instituto de Geociências da UNB, 70910-900, Brasília,DF, E-mail: rventura@unb.br
} 
revelam que estas rochas têm interação limitada com fluidos durante o metamorfismo, comportando-se como barreiras relativamente impermeáveis aos fluidos externos (Peters \& Wickham 1995, Hoefs 1997). Em conseqüência, as camadas carbonáticas em geral preservam a composição isotópica original, enquanto os fluidos tendem a ser canalizados pelas camadas pelíticas (Valley et al. 1986, Baker 1990). Baker \& Mathews (1995) discutem os efeitos da infiltração retrógrada em mármores e metapelitos secionados por veios calcissilicáticos, isotopicamente mais leves, e documentam reduções de até $12 \%$ nos mármores e de até $4 \%$ nos pelitos. Os estudos em rochas carbonáticas têm sido realizados também com vistas à investigação do papel dos fluidos na geração de terremotos e falhas atualmente ativos. Pili et al. (2002) realizaram análises isotópicas de carbono e oxigênio em calcários da Falha de San Andreas e sugerem um mecanismo complexo envolvendo mistura de fluxos penetrativos e canalizados para a região.

Por outro lado, os fluidos associados a zonas de cisalhamento desenvolvidas sob temperaturas diversas estão intimamente relacionados ao tipo de metamorfismo, estilo da deformação, transporte de massa e de calor, padrão sísmico e à gênese dos depósitos minerais nestas regiões. Nestes locais, o fluxo de fluidos normalmente causa retrogressão e retrabalhamento, produzindo mudanças nas composições mineralógica, isotópica e química das rochas envolvidas por meio de metassomatismo e reequilíbrio isotópico (Cartwright \& Buik 1999, Cartwright et al. 2000). Estudos sobre a variação na composição isotópica de oxigênio em zonas de cisalhamento de baixo grau (entre 400 a $450^{\circ} \mathrm{C}$ ) revelam uma redução geral de cerca de 2 a $4 \%$ nos valores de $\delta^{? 18} \mathrm{O}$ em rocha total e de cerca de $3 \%$ em quartzo, das amostras indeformadas para as deformadas (McCaig et al. 1990). Por exemplo, estudos realizados na zona de cisalhamento de Diadema enfatizam como a heterogeneidade dos mecanismos deformacionais ao longo de uma zona de cisalhamento pode afetar a composição isotópica de carbonatos (Oliveira \& Santos 2003). Nesse estudo, os autores mostram que variações isotópicas de oxigênio e carbono ao longo da zona de cisalhamento de Diadema associam-se à transtensão e transpressão, sendo que nesse último, ocorre devolatilização de $\mathrm{CO}_{2}$ por reações metamórficas. Em zonas mais profundas esta redução pode chegar a $10 \%$ (Kerrich et al. 1984).

A jazida fósforo-uranífera de Itataia, foco deste trabalho, está associada a rochas metacarbonáticas cuja origem vem sendo discutida por diversos pesquisadores (Campos et al. 1976, Angeiras et al. 1978, Fyfe 1979, Favali 1982, Saad 1982, Neto 1983, Mendonça et al. 1984). A jazida é constituída principalmente por colofanitos que ocorrem em corpos irregulares, maciços e em veios, associados preferencialmente a corpos lenticulares de mármores e de rochas calcissilicáticas intercaladas em rochas metapelíticas e metapsamíticas meso a neoproterozóicas metamorfisadas na fácies anfibolito alto. Os colofanitos ocorrem ainda disseminados em pegmatitos feldspáticos filoneanos, quando estes recortam rochas carbonáticas mineralizadas. A cubagem da jazida indicou uma reserva de 142.500 t de minério com teor médio de $0,19 \%$ de $\mathrm{U}_{3} \mathrm{O}_{8}$, e $18 \mathrm{Mt}$ de minério de fosfato com teor médio de 26,35\% de $\mathrm{P}_{2} 0_{5}$ (Mendonça et al. 1984). Embora conhecida há mais de 30 anos, ainda há controvérsias sobre a origem da mineralização. Três hipóteses se destacam : 1 - relacionada a epissienitos formados a partir de granitos pós-orogênicos férteis, localizados ao longo de zonas de alívio, submetidos à ação de fluxos convectivos deutéricos. (Campos et al. 1976, Angeiras et al. 1978, Fyfe 1979, Neto 1983); 2 - relacionada a um pacote de sedimentos depositados em zonas de plataforma marinha, com posterior transformação e enriquecimento de urânio por metassomatose sódica, durante o metamorfismo (Favali 1982, Saad 1982); 3- relacionada a dois tipos de mineralizações i) uma mineralização de urânio associada aos epissienitos sendo, entretanto, empobrecida em P2O5, e ii) uma mineralização fósforo-uranífera de origem sedimentar, a qual estaria associada a rochas formadas a partir da acumulação de restos fosfáticos e carbonosos em depressões plataformais, próximas ao litoral, com baixo $\mathrm{pH}$ e condições redutoras (Mendonça et al. 1984).

O presente trabalhose baseia em uma reavaliação dos dados de testemunhos de sondagem, trabalhos de campo, tipologia do minério e estudo de isótopos estáveis (carbono e oxigênio em carbonatos), e visa contribuir para uma melhor caracterização do ambiente de formação das rochas carbonáticas e a origem dos fluidos em equilíbrio com os carbonatos e, consequentemente, a origem da mineralização de fósforo-uranífera dessas rochas.

ASPECTOS GEOLÓGICOS A província fósforo-uranífera de Itataia está localizada no Município de Santa Quitéria-Ceará, porção central do Ceará (Fig. 1), englobada no Domínio Ceará Central (Arthaud et al. 1998, Fetter 1999). Segundo esses autores, este domínio é caracterizado por uma tectônica tangencial com nappes envolvendo gnaisses e migmatitos do embasamento policíclico (Transamazônico e Brasiliano) e rochas metassedimentares proterozóicas. Embasamento e rochas supracrustais, foram atingidos por metamorfismo da fácies xisto-verde a granulito.

Quatro unidades geotectônicas destacam-se no domínio Ceará Central (Martins 2000): (i) coberturas meso a neoproterozóicas de rifte-plataforma, caracterizadas por seqüências metapsamopelítica-carbonáticas agrupadas sob diferentes denominações, tais como Grupo Ceará, Grupo Itataia e Grupo/Complexo Independência; (ii) terreno Santa Quitéria, constituído por rochas gnáissicas e migmatíticas de composição tonalítica a granodiorítica, provavelmente derivado da mistura de rochas do embasamento paleoproterozóico (ca. 2,1 Ga) e material neoproterozóico; (iii) terrenos acrescionários do Paleoproterozóico relacionados à Orogênese Transamazônica, constituídos por anfibolitos com e sem granada, paragnaisses, quartzitos, metaconglomerados, ortognaisses tonalítico-graníticos agrupados sob a denominação de Suite Metamórfica Algodões-Choró; (iv) núcleo máficoultramáfico arqueano, representado pelo Maciço de Tróia.

A área da jazida de Itataia contém duas dessas unidades. A mais antiga, do paleoproterozóico $(\sim 2,1 \mathrm{Ga})$, compreende terrenos granito-gnáissicos granodioríticos a tonalíticos, em parte migmatizados. Nesta unidade insere-se o Complexo Tamboril Santa Quitéria de Castro (2001), ao qual se associam vários corpos graníticos e pegmatóides brasilianos e rochas máficas e ultramáficas de idade indefinida. A segunda consiste de uma seqüência supracrustal meso- a neoproterozóica composta por rochas metassedimentares terrígenas com predominância de xistos e gnaisses a duas micas, granada e sillimanita contendo intercalações lenticulares de gnaisses calcissilicáticos, quartzitos, anfibolitos, leptinitos e camadas de mármores calcítico e dolomítico, referidas na literatura como Grupo Itataia (Fig.1) (e.g. Mendonça et al. 1982). Por hospedar o depósito fósforo-uranífero merecerá maior ênfase neste trabalho.

A semelhança do Domínio Ceará Central, as rochas metassedimentares pelíticas da região de Itataia agrupadas na unidade Grupo Itataia (formações Serra do Céu e Barrigas) são dominantemente aluminosas e marcados pela presença de sillimanita nos metapelitos, o que indica que todos os litotipos dessa região recristalizaram-se em condições de fácies anfibolito 

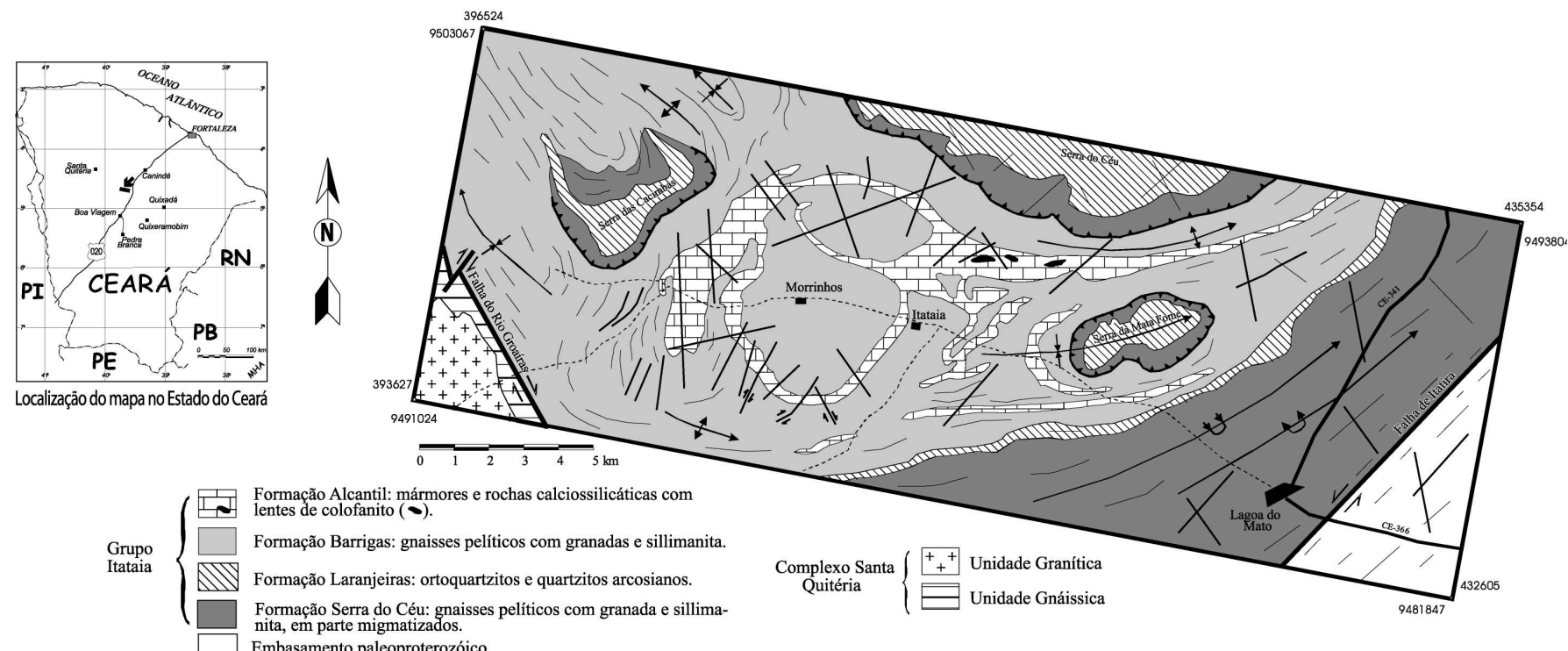

Figura 1 - Mapa de localização e geológico da área (modificado de Mendonça et al. 1984 e Santos 2003).

alto. Entretanto, em alguns locais, sobretudo na base de algumas unidades, próximo às zonas de cavalgamento, ocorre cianita reliquiar, o que sugere condições pretéritas de mais alta pressão. Veios de quartzo com megacristais de rutilo e a presença de granada nos anfibolitos são argumentos complementares a esta hipótese. Os quartzitos (Formação Laranjeiras), por sua vez, se intercalam nos metapelitos (formações Serra do Céu e Barrigas) e sustentam as principais elevações da área. Ora ocorrem como lentes de extensão quilométrica, com granocrescência e aspecto maciço em direção ao topo (Serra do Céu) e com leitos ferruginosos no topo (Serra das Cacimbas) (Santos 2003); ora ocorrem em corpos tabulares de largura métrica e extensão quilométrica. Variam de quartzitos arcosianos a quartzitos com sillimanita e ortoquartzitos. São também comuns mobilizados pegmatóides e veios de quartzo com rutilo junto às rochas metassedimentares terrígenas.

Veios de leucossoma sub-concordantes com a foliação são comuns nos xistos aluminosos das formações Serra do Céu e Barrigas, e podem atingir cerca de 20 a $40 \%$ do volume dessas rochas. Nos anfibolitos os leucossomas contêm hornblenda, o que implica em temperaturas de pico metaórfico da ordem de $700^{\circ} \mathrm{C}$. Em geral, o leucossoma dos metapelitos apresenta evidências de deformação sob alta temperatura, marcada por microestruturas porfiroclásticas de feldspato potássico acompanhadas de bandas de cisalhamentos com sillimanita sincinemática.

Os anatexitos ocorrem em faixas de alguns metros a várias centenas de metros de espessura. São rochas venuladas e bandadas que se associam a metatexitos com estruturas schlieren materializadas por concentrações residuais de biotita, pobres em sillimanita e a diatexitos graníticos com xenólitos/boudins de rochas calcissilicáticas. Encaixados nessas rochas encontram-se, ainda, corpos granitóides com megacristais de feldspato potássico e turmalina, por vezes com granada e sillimanita. Numerosos aplitos os recortam também, assim como um volumoso número de filões pegmatíticos com muscovita, de espessura métrica a decamétrica.

As rochas metassedimentares do Grupo Itataia foram afetadas por uma tectônica compressional regional, responsável pela geração de dobras isoclinais apertadas e recumbentes, com foliação plano axial de baixo ângulo de mergulho para NW, e transporte tectônico para sul. Essa deformação foi sucedida por uma importante deformação rúptil a dúctil-rúptil responsável pela brechação dos pegmatitos, por falhas e fraturas conjugadas ou não.

JAZIMENTOFÓSFORO-URANÍFERO DE ITATAIA Odepósito fósforo-uranífero é composto por colofanito que ocorre sob diferentes formas e associações e se concentra preferencialmente em mármores e rochas calcissilicáticas (Formação Alcantil). As lentes de gnaisses calcissilicáticos representam antigos leitos cálcio-ferromagnesianos, hoje compostos por diopsídio, tremolita, biotita-flogopita, plagioclásio cálcico, granada cálcica, quartzo e titanita. As lentes podem ser reconhecidas em três associações litológicas: (a) leptinitos e paragnaisses; (b) lentes e blocos de anfibolito; e (c) mármores, quando, então, as rochas calcissilicáticas normalmente contêm escapolita, algumas verdadeiros escapolititos com até $70 \%$ em volume do mineral, o que indica tratarem-se de antigas lamas calcárias dolomíticas, traduzindo um ambiente evaporítico (e.g. Parente et al. 1996).

Os leptinitos têm biotita como o único mineral ferromagnesiano, são pobres em granada e ocorrem em camadas de dezenas de metros de espessura em meio aos metapelitos. Essas rochas podem ser interpretadas tanto como antigos leitos de arenitos arcosianos assim como antigos sills de riolito ou de microgranito.

Os anfibolitos são em geral granatíferos, de composição próxima a metamafito, derivados possivelmente de tufos máficos ou mesmo de sills de diabásios, que se alojaram preferencialmente nas rochas carbonáticas em um ambiente plataformal marinho raso.

Os mármores ocorrem desde lentes descontínuas de espessura métrica a camadas relativamente contínuas com espessura em torno de $300 \mathrm{~m}$ em meio aos metapelitos, em diferentes porções estratigráficas. Variam de mármores calcíticos relativamente puros a mármores dolomíticos impuros, nos quais são comuns diopsídio, escapolita e grafita. Sua granulação varia de fina $(\sim 2 \mathrm{~mm})$ a grossa $(1 \mathrm{a} 2 \mathrm{~cm})$. A fácies mais grossa, relativamente estreita $(\sim 20 \mathrm{~m})$ é descontínua e se extende por cerca de $500 \mathrm{~m}$. Os mármores apresentam direção bastante variada, resultante de dobras e cavalgamentos. Um dos cavalgamentos é reconhecível em seção estratigráfica de furos de sondagem (Fig. 2), e é marcado pela 
superposição de dois conjuntos carbonáticos, separados por milonitos retromórficos, brechas de falhas e/ou de dissolução associadas com a carstificação. Estes litotipos, os gnaisses cálcissilicáticos e biotita gnaisses concentram e/ou hospedam as principais ocorrências fósforo-uraníferas de Itataia.

Corpos pegmatíticos centimétricos a métricos, alguns

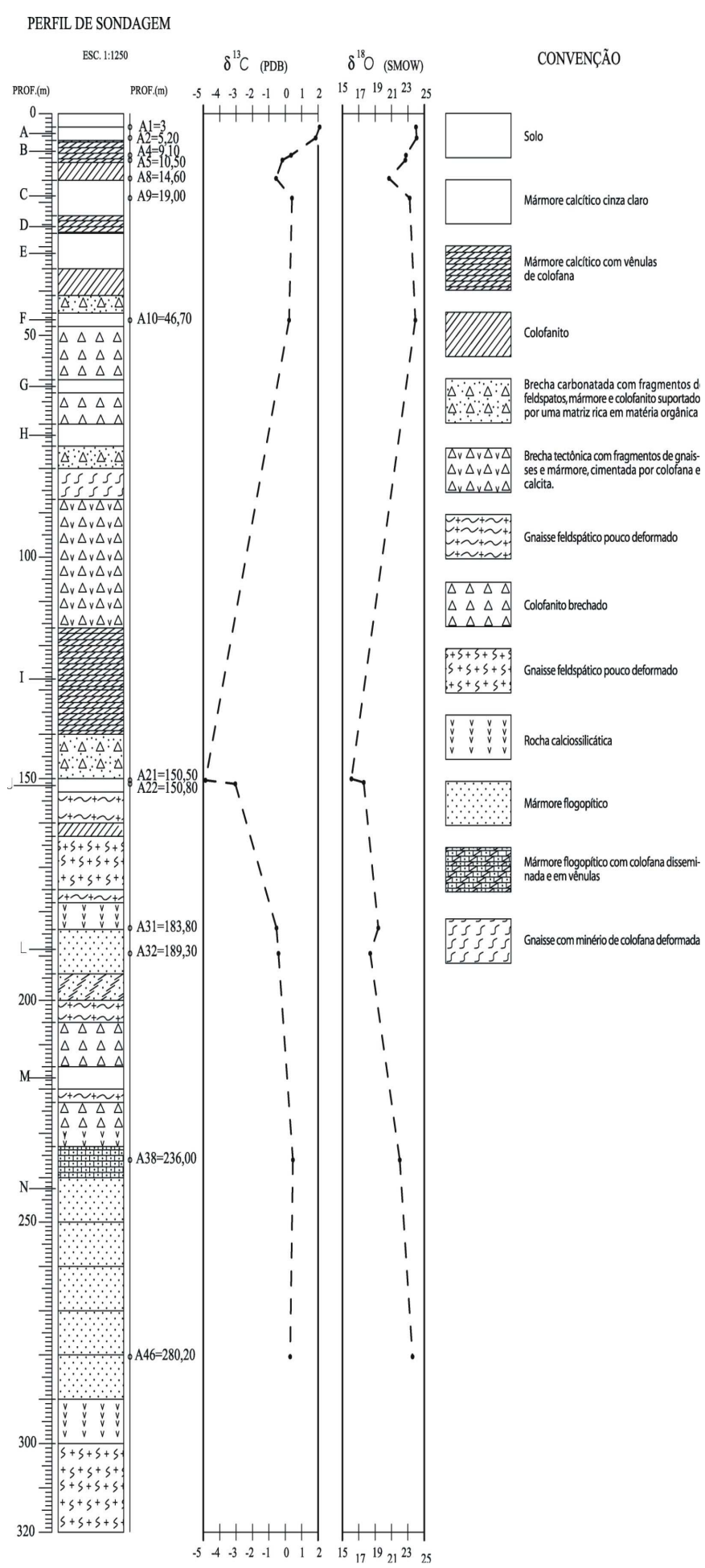

Figura 2 - Seção litoestratigráfica da jazida de Itataia. indeformados, com muscovita e turmalina, cortam os metapelitos e seus mobilizados anatéticos, enquanto outros, mais ricos em plagioclásio e pobres em filossilicatos, seccionam diferentes camadas de mármores e estão parcialmente boudinados. Em geral, quando os pegmatitos cortam camadas de mármore mineralizado, estão impregnados com colofana disseminada, sobretudo ao longo do contato, o que indica tratar-se de minério remobilizado (Fig. 3). Quando mineralizados, esses corpos têm sido referidos como "epissienitos" (e.g. Campos et al. 1976, Angeiras et al. 1978, Neto 1983). Entretanto, o termo episienito, como originalmente empregado por Sarcia \& Sarcia (1962) no Maciço Central françês, é utilizado para rochas graníticas, leucocráticas ou não, que, alteradas hidrotermalmente, são afetadas pela dissolução de quartzo primário, acompanhada, em geral, por albitização, cloritização e enriquecimento de urânio. Os principais minerais de urânio dos episienitos clássicos da França compreendem pechblenda e coffinita, ausentes nas rochas estudadas, nas quais o principal mineral minério de urânio de Itataia é a colofana, apatita amorfa de origem sedimentar, característica dos depósitos fosforíticos.

TIPOLOGIA DO MINÉRIO O depósito de Itataia contém pelo menos 5 tipos de minério, que, segundo a importância econômica compreendem: (a) colofanito maciço situado especialmente no topo da seqüência de mármores e que sustenta pequena elevação associada a mármores brechados; (b) associado a brechas carbonosas e não carbonosas; (c) veios de pequena espessura que cortam mármores e a foliação milonítica; (d) disseminado em pegmatitos e (e) disseminado em gnaisses pelíticos e calcissilicáticos deformados e acompanhando o bandamento ou a foliação milonítica.

Colofanito maciço É um minério de granulação fina, maciço, rosa a vermelho tijolo, com local hábito botrioidal. É composto de colofana e se concentra no topo da seqüência carbonática superior onde preenche cavidades métricas de carste (Fig. 4). Ao microscópio, o colofanito exibe um mosaico de esferuliltos com cristais de colofana fibrorradiada e de concentrações microcristalinas de quartzo (calcedônia) em cavidades, fraturas e poros. Os esferulitos são formados por apatita com inclusões de partículas opacas pretas a marrom avermelhadas e massas criptocristalinas isotrópicas de colofana. Este conjunto forma 80 a $90 \%$ da rocha e os esferulitos unem-se por contornos poligonais.

Brechas carbonosas São de granulação fina a média, cinzaescuro a cinza-médio, textura fragmentária, com fragmentos milimétricos a centimétricos de rocha feldspática fina, colofanito, mármore com lamelas de grafita e rocha calcissilicática, suportados por matriz carbonosa (Fig.5). O material escuro das brechas pode aparecer ora cimentado pelo colofanito, ora como matriz, que demonstra mais de uma fase de colofanito. Em meio à matriz carbonosa também ocorre calcedônia dispersa e em fraturas, pirita em pequenos cristais automórficos, zircão idiomórfico, montmorilonita e clorita.

Brechas não carbonosas mineralizadas Contêm fragmentos angulosos de mármore desde alguns milímetros até $30 \mathrm{~cm}$, envolvidos por matriz avermelhada de colofana. Alguns fragmentos estão impregnados por colofana intergranular, da periferia para o centro dos clastos, traduzindo substituição metassomática. No geral, a fragmentação do mármore foi acompanhada por dissolução e recristalização de calcita em megacristais de 1 a 20 cm, carac- 
terísticos de recristalização em zonas cársticas. Isto é observado ao longo da galeria G3 e em furos de sonda, particularmente no F119 , o qual interceta toda a seqüência mineralizada. Na profundidade de $144 \mathrm{~m}$ ocorrem zonas brechadas, marcadas por fragmentos subangulosos a subarredondados de colofanito e mármore de 1 a $10 \mathrm{~cm}$ de diâmetro, com disseminações de colofana, ligeiramente rotacionados e cimentados por goethita, colofana e calcita (Fig. 6). A goethita ocorre como fina película sobre os fragmentos, que normalmente apresentam bordas de dissolução, acompanhados de colofana neoformada com textura coloforme e de megacristais tardios de calcita de até $10 \mathrm{~cm}$, cristalizados em aberturas. A presença desses cimentos dos fragmentos de mármore com minério disseminado pode indicar uma origem por infiltração de soluções aquosas de baixa temperatura (água meteórica) ao longo de juntas

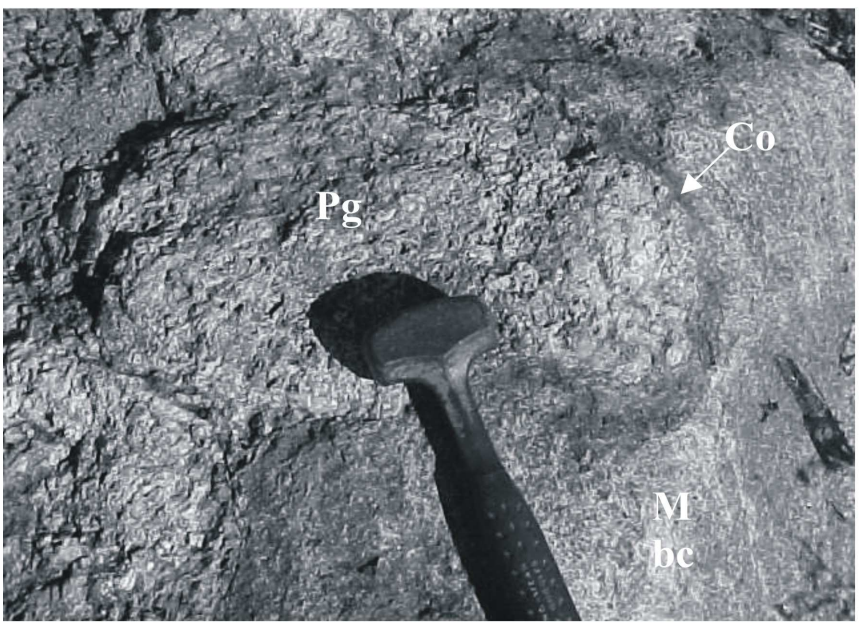

Figura 3 - Corpos pegmatóides contendo megacristais de plagioclásio e K-feldspato que recortam mármores da jazida fósforo uranífera de Itataia. Notar que o minério colofanito se concentra preferencialmente na zona de contato entre ambos, resultado de remobilização. Pg-Pegmatitos filoneanos; $M b c-$ Mármore calcítico $\cdot$ Con- Colnfonitn

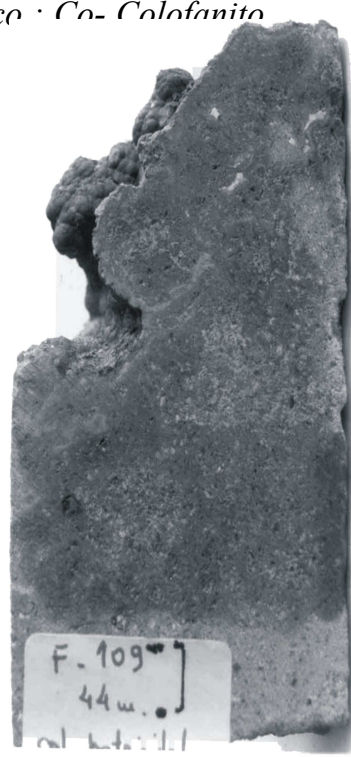

Figura 4 - Colofanito maciço com colofana botrioidal preenchendo cavidades cársticas.

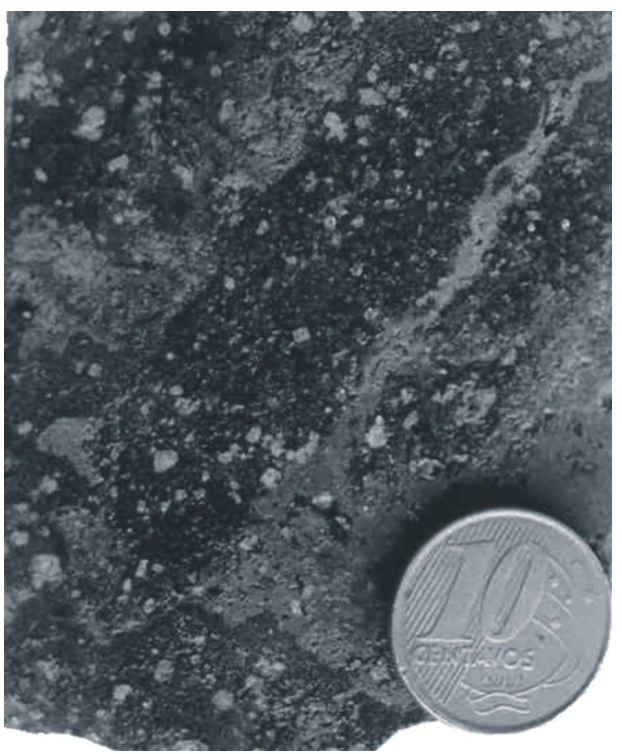

Figura 5 - Brecha carbonosa constituida de fragmentos de rocha feldspática, colofanito, mármore e calcissilicática em matrix cinza escura de grafita e matéria orgânica amorfa.

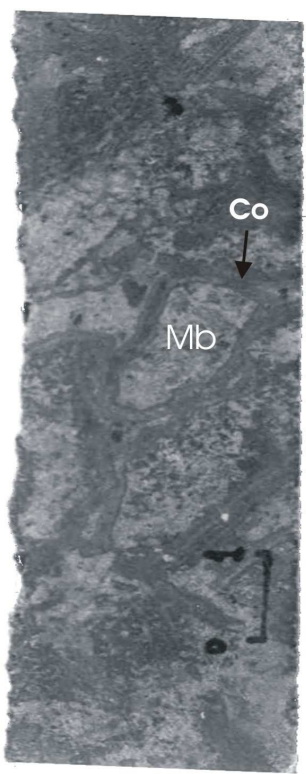

Figura 6 - Brecha de dissolução cárstica com fragmentos subangulosos a subarredondados de colofanito e mármore de 1 a $10 \mathrm{~cm}$ de diâmetro, com disseminações de colofana, ligeiramente rotacionados e cimentados por hidróxidos de ferro, colofana e calcita. Mb-Mármore ; Co-colofana.

e/ou fraturas que interceptam o protominério, a uma profundidade de até 150m, acompanhados da dissolução de carbonatos e cristalização de megacristais de calcita nos espaços mais abertos, característicos de brechas de dissolução cárstica.

Veios São de pequenas dimensões, cortam os mármores e a foliação milonítica e, por vezes, com geometria de stockwork. Ocor- 


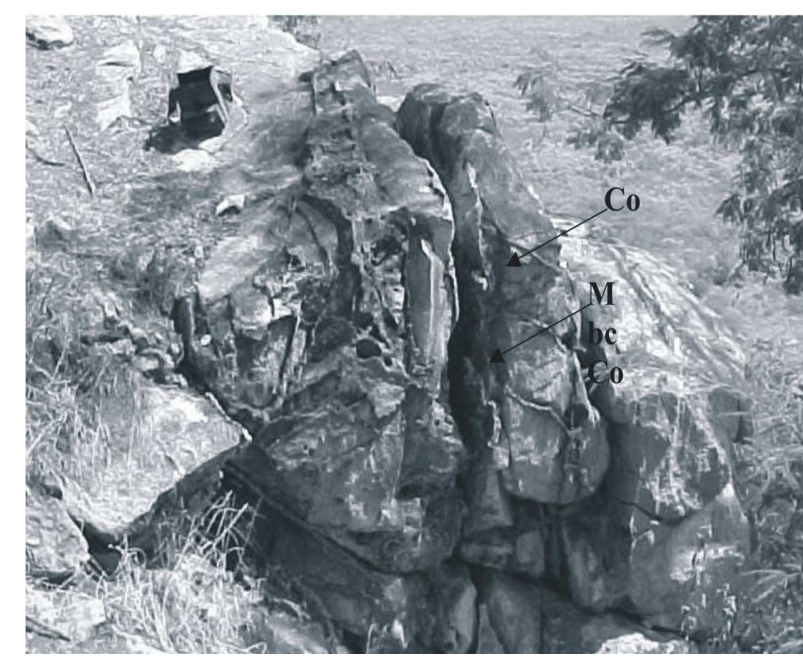

Figura 7 - Colofanitos em veios, de espessura centimétrica, ao longo de fraturas irregulares em mármores. Co- Colofanito; Mbc-Mármore calcítico

rem até a profundidade de $144 \mathrm{~m}$. (Fig.7), quando diinuem ou mesmo estão ausentes.

Pegmatitos filoneanos São corpos róseo-avermelhados, espessura métrica que ocorrem principalmente próximo à jazida, onde recortam tanto a seqüência gnáissica quanto a metacarbonática. Em geral possuem granulação grossa, textura pegmatóide, por vezes vacuolar, e contêm colofana disseminada, de aspecto terroso amarelo-ocre a marrom, sobretudo nas bordas com as hospedeiras (Fig. 3).

Gnaisses pelíticos e rochas calcissilicáticas Possuem colofana disseminada, principalmente ao longo da foliação milonítica, em parte anastomosada (Fig. 8). Trata-se de minério de baixo teor, mas importante do ponto de vista genético, pois assinala o caráter prédeformacional da mineralização.

A área da mina onde foram abertas galerias apresenta várias falhas normais, subverticais, que cortam as rochas encaixantes da jazida. Estas são mármores calcíticos a dolomíticos, por vezes grafitosos, com intercalações de rochas calcissilicáticas dobradas e boudinadas, posteriormente cortadas por filões de pegmatitos de espessura métrica. Próximo às fraturas, as hospedeiras do minério e os pegmatitos estão brechados e impregnados com colofana. A brechação foi acompanhada de alteração de baixa temperatura marcada por dissolução de quartzo, estrutura vacuolar, caulinização e sericitização dos feldspatos.

Na galeria G3, paralela a uma falha normal E-W, a alteração secundária, particularmente supergênica, é importante, normalmente desenvolvendo-se ao longo de falhas normais e fraturas. Há pelo menos quatro conjuntos de falhas, dos quais três subverticais :i) falhas com direção NW-SE; ii) falhas NE-SW e formam, localmente, par conjugado com o primeiro, e iii) falhas normais E-W. O quarto conjunto é representado por falhas e fraturas de E-W, suborizontais. Essas foram importantes canais de percolação de fluidos mineralizados em colofana, algumas vezes caulinita ou carbonato, o último resultado de dissolução e reprecitação nas intersecções de fraturas, onde ocorre em bolsões de colofanito

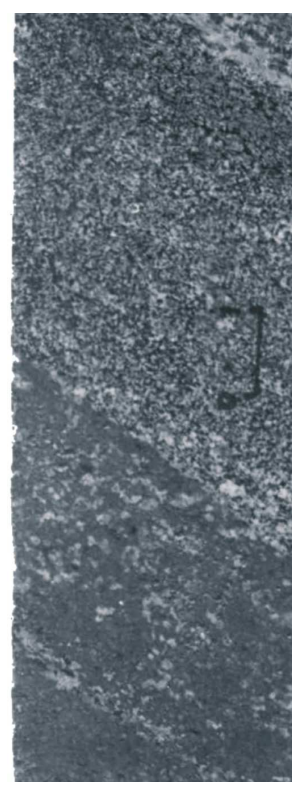

Figura 8 - Gnaisses pelíticos bandados e deformados contendo intercalações de camada centimétrica de colofanito ao longo da foliação tectono-metamórfica. Gn- Gnaisse pelítico; CoColofanito

como calcita, alguns dos quais com $20 \mathrm{~cm}$ de comprimento. Nessas fraturas, o colofanito tem espessura de alguns centímetros a decímetros, sendo mais espessos nas intersecções. Embora pulverulentos, certos protólitos são reconhecíveis, tais como leitos de rochas cálcissilicáticas com tremolita, biotita e grafita. São comuns blocos centimétricos a métricos, angulosos, fraturados de mármore com substituição progressiva, das bordas para o centro dos blocos, do carbonato por colofanito na forma de impregnações intergranulares em manchas esparsas.

Em geral, a brechação foi acompanhada pela dissolução do mármore e recristalização de megacristais de calcita, o que implica em carstificação. Contudo, não foram encontrados estalactites e estalagmites, apenas a formação de travertino recente, fato que demonstra a presença de mais de um processo de carstificação. Silva (2003) sublinha a existência de dois processos de carstificação na área, um de idade cambro-ordoviciano, que seria em grande parte responsável pela mineralização fósforo-uranífera e outro de idade quaternária, responsável pela neoformação de travertino.

GEOQUÍMICAISOTÓPICA Amostragem, Procedimentos Analíticos e Resultados Isótopos de Carbono e Oxigênio foram analisados em treze amostras. Essas foram coletadas ao longo de uma seção de sondagem (F-119) que corta a zona mineralizada com colofanito (Fig. 2), estão metamorfisadas na fácies anfibolito e, em parte, retrometamorfisadas na fácies xisto verde. A seção contém cerca de treze camadas de mármore calcítico e/ou dolomítico, com espessuras entre 1 e $60 \mathrm{~m}$, intercaladas com camadas de rochas calcissilicáticas, colofanito e rochas metassedimentares terrígenas representadas por biotita-gnaisses feldspáticos, em parte milonitizados, e por brechas tectônicas e / ou de dissolução. Para efeitos de simplificação, as diferentes camadas serão aqui informalmente designadas, sem conotação litoestratigráfica, por Camada A-2 amostras, B-2, C -2, F - 1, J - 2, $\mathrm{L}-2$ e N - 2. Os resultados obtidos constam da Tabela 1. 
As análises isotópicas foram realizadas no Laboratório de Isótopos Estáveis (LABISE) da Universidade Federal de Pernambuco. As amostras (10 a $20 \mathrm{mg}$ ) foram dissolvidas com ácido fosfórico a $100 \%$ e a $25^{\circ} \mathrm{C} . \mathrm{O} \mathrm{CO}_{2}$ liberado dessa reação, após ser criogenicamente purificado (armadilha com nitrogênio líquido + álcool para remover a água resultante da reação do carbonato com ácido fosfórico), foi analisado em um espectrômetro de massa de fonte gasosa (SIRA II) de dupla admissão, triplo coletor, usando o gás de referência BSC (Borborema skarn calcite), calibrado segundo padrões internacionais (NBS-18, NBS-19, NBS20).

Os valores de $\delta^{13} \mathrm{C}$ e $\delta^{18} \mathrm{O}$ dos carbonatos analisados ao longo do testemunho de sondagem, tendo como referência os padrões PDB para Carbono e SMOW para Oxigênio, são apresentados na Tabela 1. Nas figuras 2 e 9 estes dados são plotados em função da profundidade da amostra ao longo do testemunho, o que revela que na porção central do perfil os valores de $\delta^{13} \mathrm{C}(-5,0$ a $-0,5 \%)$ e $\delta^{18} \mathrm{O}(+16,4 \mathrm{a}+19,2 \%$ o são significativamente mais negativos que os das porções superior e inferior, onde o $\delta^{13} \mathrm{C}$ varia de $-0,6$ a $+2,0 \%$ e o $\delta^{18} \mathrm{O}$ varia de $+20,9 \mathrm{a}+24,3 \%$.

DISCUSSÃO Variações isotópicas de C e O em metacarbonatos de Itataia Os carbonatos das amostras estudadas apresentam variação significativa na composição isotópica de carbono e oxigênio, mesmo considerando-se as diferentes associações mineralógicas. A figura 10, que apresenta os dados isotópicos num gráfico de $\delta^{13} \mathrm{C}$ versus $\delta^{18} \mathrm{O}$, mostra que as amostras de Itataia distribuem-se ao longo de uma reta e indica que os processos de interação isotópica afetaram simultaneamente os isótopos de $\mathrm{C}$ e O. Em geral, a composição isotópica de carbonatos presentes em rochas carbonáticas metamorfisadas (e.g. Hoefs 1997) pode ser controlada por vários fatores, tais como: i) a composição do protólito pré-metamórfico; $i i)$ reações metamórficas e de reequilíbrio isotópico induzidas por aumento de temperatura, que podem estar ou não associadas a processos de liberação de $\mathrm{CO}_{2}$ por devolatilização e; iii) interações rocha-fluido, fluidos estes derivados de processos tardi a pós-magmáticos, metamórficos ou meteóricos.

Os valores primários de isótopos de $\mathrm{C}$ e $\mathrm{O}$ em carbonatos tendem a ser modificados por processos metamórficos, mesmo nos casos em que o metamorfismo tenha ocorrido em sistema fechado (Eiler et al. 1992, Farquhar et al. 1993). Nessas situações, os isótopos de oxigênio em carbonatos de rochas carbonáticas impuras seriam mais susceptíveis a modificações em função de trocas isotópicas com outras fases minerais que também possuem oxigênio, tais como silicatos. No caso de Itataia, os mármores mais puros $\left(\delta^{13} \mathrm{C}\right.$ entre $+0.3 \mathrm{e}+2.0 \%$ e de $\delta^{18} \mathrm{O}$ entre $+22,9 \mathrm{e}+24,3 \%$ ) e que apresentam menos evidências de interações com fluidos estão posicionados na porção superior do testemunho de sondagem e na camada $\mathrm{N}$, esta última por ser mais espessa, é a que melhor preserva as feições do protólito pré-metamórfico. Ressalta-se que as camadas de mármore mais puros apresentam permeabilidade mais baixa, limitando desta forma interações da rocha com fluidos hidrotermais (Peters \& Wickhamm 1995, Hoefs 1997). Entretanto, a presença de uma associação metamórfica da fácies anfibolito alto na camada $\mathrm{N}$, marcada pela presença de minerais silicáticos, em particular diopsídio, pode indicar que reações de volatilização tenham modificado as razões isotópicas primárias.

Considerando que as amostras da porção superior do testemunho representam valores mais preservados dos carbonatos de Itataia e que estas amostras foram afetadas por processos que levaram à diminuição simultâneas dos isótopos de $\mathrm{C}$ e $\mathrm{O}$, dois

Tabela 1 - Caracterização mineralógica e isotópica de amostras de mármore do furo de sondagem F.119 da jazida fósforouranifera de Itataia, CE.

\begin{tabular}{|c|c|c|c|c|c|c|}
\hline Amostras & $\begin{array}{l}\text { Prof. } \\
(\mathrm{m})\end{array}$ & Nível & Associação mineral & $\begin{array}{c}\delta^{18} \mathrm{OSMO} \\
\mathrm{W}\end{array}$ & $\begin{array}{c}\delta^{18} \mathrm{OPD} \\
\mathrm{B}\end{array}$ & $\begin{array}{c}{ }^{13} \mathrm{CPD} \\
\mathrm{B}\end{array}$ \\
\hline A01 & 3.0 & A & Calcita, quartzo, grafita. & 24.0 & -6.7 & 2.0 \\
\hline $\mathrm{A} 02$ & 5.2 & A & Calcita, calcedônia, adularia, grafita & 24.3 & -6.4 & 2.0 \\
\hline $\mathrm{A} 04$ & 9.1 & B & Calcita,siderita calcedônia, muscovita, grafita. & 23.0 & -7.7 & 0.3 \\
\hline A05 & 10.5 & B & $\begin{array}{l}\text { Calcita, flogopita, quartzo, adularia, tremolita, grafita, } \\
\text { (arfvedsonita), pirita }\end{array}$ & 22.9 & -7.7 & -0.1 \\
\hline A08 & 14.6 & $\mathrm{C}$ & $\begin{array}{l}\text { Calcita, siderita, flogopita, tremolita, arfvedsonita, quartzo, } \\
\text { muscovita, grafita. }\end{array}$ & 20.9 & -9.6 & -0.6 \\
\hline A09 & 19.0 & $\mathrm{C}$ & $\begin{array}{l}\text { Calcita, siderita, adulária, tremolita, quartzo, grafita, flogopita, } \\
\text { arfvedsonita. }\end{array}$ & 23.1 & -7.5 & 0.4 \\
\hline A10 & 46.7 & $\mathrm{~F}$ & Calcita, siderita, mica branca, quartzo, grafita,.titanita. & 23.9 & -6.7 & 0.2 \\
\hline A21 & 150.5 & $\mathrm{~J}$ & $\begin{array}{l}\text { Dolomita/calcita, diopsídio, flogopita, opacos, titanita, mica } \\
\text { branca, zircão, quartzo. }\end{array}$ & 16.4 & -14.1 & -5.0 \\
\hline $\mathrm{A} 22$ & 150.8 & $\mathbf{J}$ & Dolomita/calcita, siderita, diopsídio, tremolita, quartzo, titanita. & 17.4 & -13.1 & -3.2 \\
\hline A31 & 183.8 & $\mathrm{~L}$ & $\begin{array}{l}\text { Dolomita/calcita/siderita, diopsídio, tremolita, flogopita, grafita, } \\
\text { zoizita, mica branca, opacos. }\end{array}$ & 19.2 & -11.3 & -0.6 \\
\hline $\mathrm{A} 32$ & 189.3 & $\mathrm{~L}$ & $\begin{array}{l}\text { Dolomita/calcita/siderita, diopsídio, adularia, microclina, } \\
\text { flogopita, clinocloro, titanita, calcedônia. }\end{array}$ & 18.6 & -11.9 & -0.5 \\
\hline A38 & 236 & $\mathrm{~N}$ & $\begin{array}{l}\text { Dolomita/calcita, tremolita, flogopita, clinocloro, opacos, titanita, } \\
\text { quartzo. }\end{array}$ & 22.0 & -8.6 & 0.5 \\
\hline A46 & 280.2 & $\mathrm{~N}$ & Dolomita/calcita, diopsídio, flogopita, clinocloro, biotita, quartzo. & 23.6 & -7.0 & 0.3 \\
\hline
\end{tabular}



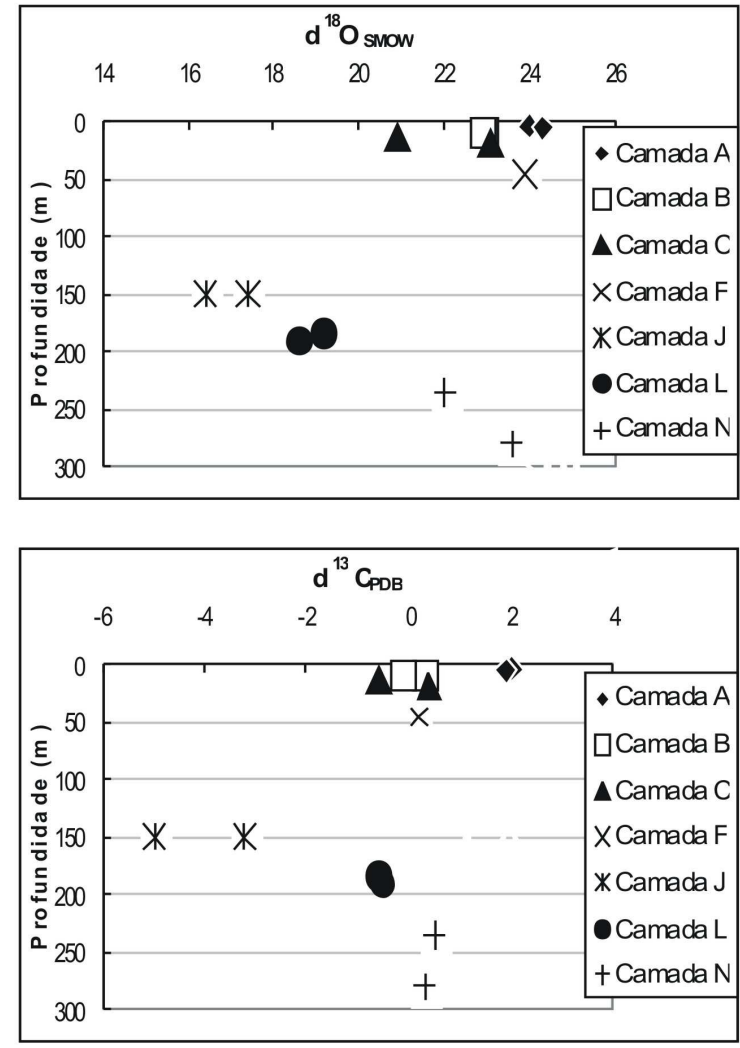

Figura 9-Diagramas a) $\delta^{18}$ OSMOW (\%o) e b) $\delta^{113} \mathrm{CPDB}(\%)$, vs Profundidade (m) para as rochas metacarbonáticas hospedeiras da jazida fósforo-uranífera de Itataia.

processos principais podem ter sido responsáveis pela diminuição simultânea dos valores de $\mathrm{C} \mathrm{e} \mathrm{O}$ : i) metamorfismo acompanhado de devolatilização de $\mathrm{CO}_{2}$; ii) interação com fluidos meteóricos a altas temperaturas.

No primeiro caso, reações metamórficas associadas a processos de descarbonatação têm como produto o $\mathrm{CO}_{2}$, que em situações de equilíbrio isotópico acima de $270{ }^{\circ} \mathrm{C}$ é enriquecido nos isótopos de $\mathrm{C}$ e $\mathrm{O}$ relativamente ao carbonato residual (Chacko et al. 1991). Nesse caso, os carbonatos e o quartzo (ou feldspatos) reagem para produzir silicatos de cálcio/magnésio mais $\mathrm{CO}_{2}$ o qual, tão logo é produzido, é expelido. A remoção de carbono e oxigênio faz com que os valores de $\delta^{13} \mathrm{C}$ e o $\delta^{18} \mathrm{O}$ sofram uma redução durante o processo de descarbonatação, sendo a magnitude desta variação dependente da temperatura e da forma de liberação do $\mathrm{CO}_{2}$. Em geral, a liberação do $\mathrm{CO}_{2}$ neste tipo de sistema obedece em geral a Lei de Rayleigh, cujas conseqüências para as composições isotópicas de $\mathrm{C}$ e $\mathrm{O}$ são distintas. Como o $\mathrm{C}$ está presente somente na fase carbonática, as variações isotópicas deste elemento é controlada somente pelo processo de devolatilização. No caso do $\mathrm{O}$, sua composição isotópica é controlada tanto pelo processo de devolatilização quanto por trocas isotópicas entre o carbonato residual e outras fases ricas em $\mathrm{O}$, que tendem a minimizar as variações isotópicas deste elemento (Valley et al. 1986). A figura 10 apresenta a evolução da composição isotópica dos carbonatos primários de Itataia assumindo um processo devolatilização segundo a Lei de Rayleigh e diferentes proporções de carbonato para silicato.

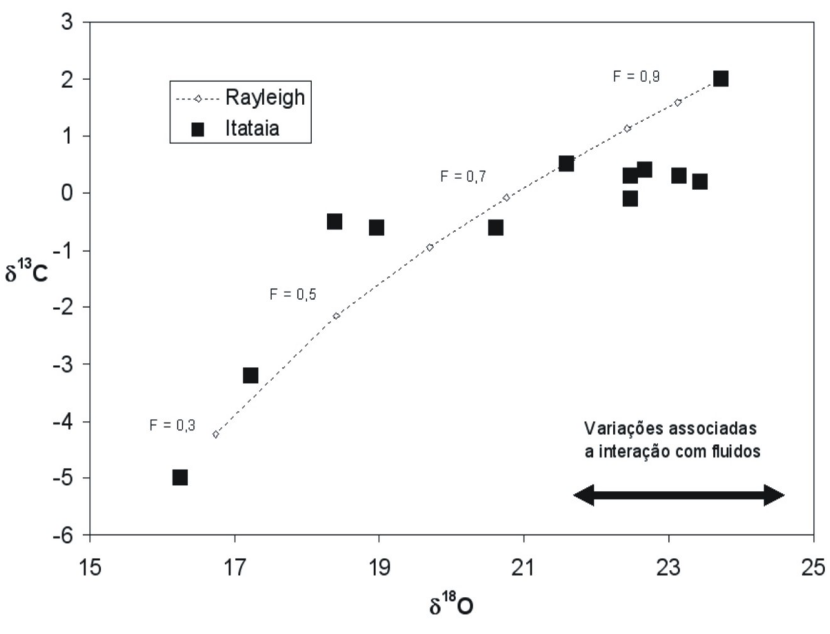

Figura 10 - Diagrama $\delta^{18} O$ versus $\delta^{13} C$ para as amostras de Itataia mostrando forte correlação positiva entre a variações isotópicas de C e O. A linha tracejada refere-se à variação da composição isotópica do carbonato primário de Itataia considerando-se devolatilização de $\mathrm{CO}_{2}$ segundo a Lei de Rayleigh e assumindo-se valores iniciais de $\delta^{18} O_{\text {SMOW }}=$ $+24,3 \%$ e de $\delta^{13} \mathrm{C}=+2,0 \%$ para os carbonatos. Os cálculos foram realizados assumindo-se ainda $\Delta^{C}{ }_{\text {CO2-CC }}=3 \%$, $\Delta^{O}{ }_{\text {CO2-CC }}$ $=6 \%$, para uma proporção de $20 \%$ de carbonato. Os valores referentes à letra F representam a fração de carbonato residual no sistema após a reação de descarbonatação.

No segundo caso, no qual as variações isotópicas estariam associadas a interações rocha-fluido, vários fatores controlariam a dinâmica do processo: mecanismos de transporte e composição isotópica dos fluidos, temperatura e reatividade da rocha. Com relação aos mecanismos de transporte de fluidos, as feições estruturais definem se seu caráter é pervasivo ou canalizado, sendo que este último caso favorece a heterogeneidade química e isotópica (Oliveira \& Santos 2003). Com relação a Itataia, os valores isotópicos mais baixos associam-se a uma zona de cavalgamento interceptada pelo testemunho de sondagem e ao longo da qual os fluidos teriam sido canalizados (Fig. 2). A presença de milonitos retromórficos, brechas de falhas e/ou de dissolução associadas com processos de carstificação ao longo dessa zona de descontinuidade estrutural reforçam essa interpretação.

Estudos sobre a composição dos fluidos terrestres revelam uma ampla variação nos valores de $\delta^{18} \mathrm{O}_{\mathrm{SMOW}}: i$ ) fluidos oceânicos $(=0 \%)$; ii) fluidos meteóricos $(<0 \%$ ), iii) fluidos magmáticos $(+5$ a $+8 \%$ ou $+6 \mathrm{a}+9 \%$ o $), i v)$ fluidos metamórficos $(+5 \mathrm{a}+14$ ou $>10 \%$ ). Assumindo-se que a zona de descontinuidade teve um papel fundamental na percolação de fluidos, seriam estes derivados de processos meteóricos, metamórficos ou magmáticos? A resposta a essa questão requer uma análise das condições de temperatura a que foram submetidos os carbonatos. Por exemplo, assumindo-se com base na paragênese metamórfica que a interação rocha-fluida ocorreu a temperaturas variando entre $200^{\circ} \mathrm{C}(\delta$ cal-água $=+8,9 \%$, O’Neil et al. 1969) e $400^{\circ} \mathrm{C}($ cal-água $=+2,7 \%$, O’Neil et al. 1969), os fluidos que interagiram com a amostra A21 ( $\delta^{18}$ Osmow $=+16,41 \%$ ) teriam $\delta^{18} \mathrm{O}$ smow entre $+7,5 \mathrm{e}+13,7 \%$. Fluidos com essa composição teriam provavelmente contribuição de processos metamórficos. Não obstante uma caracterização mais precisa 
sobre origem dos fluidos, as variações isotópicas observadas na Figura 2 sugerem que a razão fluido/rocha tende a diminuir à medida em que se afasta da zona de cisalhamento . Essa observação, juntamente com a magnitude das variações encontradas, que são muito maiores que aquelas esperadas em processos de devolatilização, indicam que o principal mecanismo responsável pela heterogeneidade isotópica em Itataia foi a percolação canalizada de fluidos. Ressalta-se que os baixos valores de $\delta^{13} \mathrm{C}$ dos carbonatos na zona de cisalhamento também reforçam a interpretação acima, uma vez que fluidos meteóricos e metamórfico/ magmáticos também são acompanhados por baixas razões $\mathrm{C}^{13}$ / $\mathrm{C}^{12}$.

Considerações sobre a origem do minério de Urânio Os resultados obtidos neste estudo isotópico permitem também auxiliar na compreensão da gênese do depósito fósforo-uranífero de Itataia.

Os processos de concentração de U associam-se em geral a alterações hidrotermais, muitas vezes acompanhados de metassomatismo sódio e potássico. Esse tipo de hidrotermalismo pode ser encontrado em várias situações geológicas, como na parte superior de corpos graníticos intrusivos, levando à formação de zonas ricas em microclina, albita e greisens, assim como associado a complexos alcalino-carbonatíticos. Nesses últimos, esse processo é denominado fenitização e pode se estender por quilômetros ao redor de intrusões alcalinas. Metassomatismo sódico e potássico são freqüentes também em granitos ricos em $\mathrm{U}$, onde em geral são associados a processos de epissientização que são caracterizados pela remobilização e remoção de quartzo (Leroy 1984, Cathelineau 1986). A relação entre o metassomatismo sódico-potássico e concentrações de U foi descrita em várias localidades, indicando que essa feição pode ser um excelente indicador prospectivo.

Como visto, parece não ocorrer ligação entre os mármores mineralizados ou não com processos metassomáticos de temperatura relativamente alta, capazes de formar episienitos ou albititos, considerados comumente como a fonte primária do depósito fósforo-uranífero de Itataia. A forte alteração de algumas rochas carbonáticas (brechas de dissolução mineralizadas ou não) e siliciclásticas (milonitos retromórficos) verificadas em profundidades de até $150 \mathrm{~m}$, que modificou sua composição mineralógica e química (Camada J- $\delta^{13} \mathrm{C}_{\mathrm{PDB}}-5 \mathrm{e}-3,2 \% ; \delta^{18} \mathrm{O}_{\mathrm{SMOW}} \sim 16 \%$ ) apresenta caracteres análogos a produtos de alteração supergênica, envolvendo interação com água meteórica, fenômeno comum em ambiente cárstico em geral. Pode-se pensar também que alguns veios sejam oriundos de hidrotermalismo associado a cavalgamentos e que interagiram com fluidos meteóricos em condições mais superficiais. Estes processos são ampliados ao longo das falhas e fraturas que interceptam o conjunto metacarbonático mineralizado, onde são acompanhados de dissolução e reprecipitação dos fosfatos uraníferos e carbonatos sob forma de veios, alguns dos quais contendo megacristais de calcita. Em níveis topográficos mais elevados ou superficiais tem-se a concentração maciça residual de colofanitos. Tudo isso assinala que a reconcentração do minério de Itataia esteve associada à intervenção de fluidos de baixa temperatura, característico de águas meteóricas ou conatas que migraram em profundidades de algumas centenas de metros..

Assim, das várias hipóteses iniciais sobre a gênese da jazida estudada, as que melhor explicam sua origem dizem respeito à sua associação com rochas sedimentares depositadas em zonas de plataforma marinha rasa e/ou restrita e que o fosfato seria originalmente oriundo do reservatório oceânico. O fluxo da solução darse-ia por meio da movimentação das águas frias dos fundos oceânicos, em correntes ascendentes que se misturariam às águas superficiais mais quentes das bordas de bacias, aumentando a concentração do $\mathrm{HPO}_{4}^{2-} \mathrm{e}$, posteriormente, precipitando o fosfato. A fonte de urânio, por sua vez, seria dominantemente terrígena, relacionada com a lixiviação do embasamento continental preexistente, que se depositaria em ambiente marinho confinado com fortes influências continentais. Pode-se pensar ainda, conforme Mendonça et al. (1984) e Castro (2001), que o urânio poderia, ser alternativamente, originário da água do mar, uma vez que a mesma apresenta uma concentração média neste elemento de 3,3 ppb e que sua extração se daria por meio de processos de substituição iônica, adsorsão em matéria orgânica ou adsorsão em fosfatos marinhos depositados em depressões litorâneas, com baixo $\mathrm{pH}$ e condições redutoras. O urânio presente na água do mar sob a forma de complexos uranilcarbonatos, $\mathrm{U}^{+6}$ seria reduzido a $\mathrm{U}^{+4} \mathrm{e}$ incorporado à estrutura do carbonato-flúor-apatita. Posteriormente, a ocorrência fósforo-uranífera seria mobilizada durante a diagênese e o metamorfismo e, localmente, por corpos pegmatíticos , seguindo-se uma reconcentração por processos supergênicos mediante a circulação de águas aciduladas que promoveriam a solubilização do carbonato.

CONCLUSÕES Alitoestratigrafia da região de Itataia é marcada pela superposição de diferentes camadas de rochas metacarbonáticas, rochas calcissilicáticas, brechas de dissolução cárstica, brechas carbonosas e colofanitos em gnaisses pelíticos milonitizados. Referidas rochas foram afetadas por um tectônica compressional de baixo ângulo em condições de fácies anfibolito alto (zona da sillimanita), gerando dobras isoclinais recumbentes, milonitização e transporte tectônico para sul.

O depósito fósforo-uranífero, constituído dominantemente por colofanito, apresenta tipologia bastante diversificada, sendo o minério mais antigo e, provavelmente, primário, encontrado disseminado junto às rochas gnáissicas pelíticas e rochas calcissilicáticas, normalmente deformadas. A mineralização mais nova e economicamente mais importante é representada pelos colofanitos maciços associados a processos de carstificação e enriquecimento supergênico. A presença de colofanitos com textura coloforme, em profundidade de até $144 \mathrm{~m}$, indica que fases aquosas superficiais prolongaram-se até àquela profundidade.

A análise das razões isotópicas sugere que os fluidos envolvidos na formação da mineralização fósforo-uranífera de Itataia são oriundos de água de mar, parcialmente modificados por fluidos meteóricos ou de água doce não magmática, como anteriormente suposto. A interação entre esses fluidos parece ter ocorrido durante estágio pós-deposicional, fato que indica que a mineralização fósforo-uranífera de Itataia foi dominantemente de origem sedimentar, reconcentrada por processos tectono-metamórficos e, posteriormente, enriquecida por processos supergênicos.

Agradecimentos Às Indústrias Nucleares do Brasil (INB) pelo acesso à área e informações geológicas sobre jazida de Itataia, à CAPES ( PROCAD, Processo 0083/01-1) pela ajuda financeira e aos revisores da RBG pelas críticas e sugestões ao manuscrito. 


\section{Referências}

Angeiras A.G., Neto A.M., Campos M. 1978. Mineralização fósforouranífera, associada a epissienitos sódicos no Pré-Cambriano cearense. In: SBG, Cong. Bras. Geol., 30, Anais, v.1, p.341-.

Arthaud M.H., Vasconcelos A.M., Nogueira Neto J.A., Oliveira F.V.C., Parente C.V., Monié P., Liégeois J.P., Caby R., Fetter A.H. 1998. Main Structural Features of Precambrian Domains From Ceará (NE Brazil). In: Intern. Conf. Basement Tectonics, 14, Abstracts, 84-85.

Baker AJ. 1990. Stable isotope evidence for fluid-rock interactions in the Ivrea Zone, Italy. J. Petrology, 31:243-260.

Baker J., Matthews A. 1995. The stable isotopic evolution of a metamorphic complex, Naxos, Greece. Contr. Miner. Petr., 120:391403.

Campos M., Braga A.P.G., Souza E.M., Silva F.A.F., França J.B. 1976. Projeto Rio Jaguaribe, Recife, CPRM/DNPM, v. 1.

Cartwright I., Buik I.S. 1999. Fluid generation, vein formation, and the degree of fluid-rock interaction during decompression of high-pressure terrains: The Schistes Lustrés, Alpine Corsica, France. Journal of Metamorphic Geology, 18:607-624.

Cartwright I., Buick I., Vry J. 2000. The time-integrated history of crustal fluid flow: Reynolds Range, central Australia. J. Geoch. Exp., 6970:353-357.

Castro G.L. 2001. Litogeoquímica e isótopos estáveis de carbono e oxigênio das rochas metassedimentares hospedeiras da jazida fósforouranifera de Itataia-Santa Quitéria, Ceará. Dissertação de Mestrado, Dep. Geol. UFC, 195p.

Cathelineau M. 1986. The hydrothermal alkali metassomatism effects on granitic rocks: quartz dissolution and related subsolidus changes. Journ. Petrol., 27:945-965

Eiler J.M., Baumgartner L.P., Valley J.W. 1992. Intercrystalline stable isotope diffusion: a fast grain boundary model. Contrib. Mineral. Petrol., 112:543-557.

Farquhar J., Chacko T., Frost B.R. 1993. Strategies for high-temperature oxygen isotope thermometry: a worked example from the Laramie anorthosite complex, Wyoming, USA. Earth Planet. Sci. Lett., 117:407-422.

Favali J.C. 1982. Contribuição ao estudo das mineralizações fosfáticas uraníferas da jazida de Itataia. Relatório Nuclebrás, Nota Técnica EFOR.PM 01/81.

Fetter A.H. 1999. U/Pb and Sm/Nd geocronological constraints on the crustal framework and geologic history of Ceará State, NW Borborema Province, NE Brazil: implications for the assembly of Gondwana. $\mathrm{PhD}$ Thesis, Dep. Geology, Kansas University, Lawrence, 164p.

Fyfe W.S. 1979. Notes on the Itataia Deposit. Rio de Janeiro, Relatório de Consultoria DNPM/DIAOP - NUCLEBRAS (inédito).

Hoefs J. 1997. Stable Isotope Geochemistry. Springer-Verlag, Berlim, $201 \mathrm{p}$.

Kerrich R., La Tour T.E., Willmore L. 1984. Fluid participation in deep fault zones: evidence from geological, geochemical and ${ }^{18} \mathrm{O} /{ }^{16} \mathrm{O}$ relations. J. Geoph. Res., 89(B6):4331-4343.

Leroy J. 1984. Episyénitisation dans les gisements d'uranium du
Bernardan (Marche):comparaison avec des gisements similares du Nord-Ouest du Masif Central français. Mineral. Dep., 19:26-35

Martins G. 2000. Litogeoquímica e controles geocronológicos da suite metamórfica Algodões-Choró, Ceará. Tese de Doutoramento, Inst. Geoc., UNICAMP, $218 \mathrm{p}$.

McCaig A.M., Wickham S.M., Taylor Jr. H.P. 1990. Deep fluid circulation in alpine shear zones, Pyrenees, France: field and oxygen isotope studies. Contr. Miner. Petr., 106:41-60.

Mendonça J.C.G.S., Campos M., Braga A.P.G., Souza E.M. 1982. Caracterização estratigráfica dos metassedimentos da região de ItataiaCeará (Grupo Itataia). In: SBG, Cong. Bras. Geol., 32, 1:325-338.

Mendonça J.C.G.S., Campos M., Braga A.P.G., Souza E.M., Favali J.C., Leal J.R.L.V. 1984. Jazida de Urânio de Itataia-CE. In: Principais Depósitos Minerais do Brasil, DNPM, v.1, pp. 121-131.

Neto A.M. 1983. Contributions à la minéralogie, à la pétrographie et à la métallogenie du gisêment phosporo-uranifère d'Itataia-CearáBrésil. Thèse de Doctorat, L'U.E.R. de Sci. Exac. Naturelles, Université de Clermont II, 225p.

Oliveira C.G., Santos R.V. 2003. Isotopic domains controlled by transtensional and transpressional sectors in the auriferous Diadema shear belt, northern Brazil. J. South Am. Earth Sciences, 16:513-522.

O’Neil J.R., Clayton R.N., Mayeda T.K. 1969. Oxygen isotope fractionation in divalent metal carbonates. J. Chem. Phys., 51:55475558.

Parente C.V., Guillou J.J., Barbosa H.S. 1996. Evaporitos pré-cambrianos $(\sim 1.8 \mathrm{Ga})$ da Faixa Orós. Revista de Geologia, 9:5-16.

Peters M.T., Wickham S.M. 1995. On the causes of ${ }^{18} \mathrm{O}$-depletion and ${ }^{18} \mathrm{O} /{ }^{16} \mathrm{O}$ homogenization during regional metamorphism; the East Humboldt Range core complex, Nevada. Contr. Miner. Petr., 119:68-82.

Pili E., Poitrasson F., Gratier J-P. 2002. Carbon-oxygen isotope and trace element constraints on how fluids percolate faulted limestones from the San Andreas Fault system: partitioning of fluid sources and pathways. Chem. Geol., 190:231-250.

Saad S. 1982. Proposição de um novo modelo genético para a Jazida de Itataia, Ceará. Nota Técnica nº 02 DIGEO, PM/82.

Sarcia J. \& Sarcia J. A. 1962. Les minerais uranifères français, II, PUF, Paris.

Santos A.A. 2003. Caracterização litoestrutural e geocronológica da região fósforo-uranífera de Itataia-Ce. Dissertação de Mestrado, Dep. Geol., UFC, 100p.

Silva J.R.A. 2003. Caracterização hidrogeológica da Jazida de Itataia, Ce. Dissertação de Mestrado, Dep. Geol., UFC, 156p.

Valley J.W., Taylor Jr. H.P., O’Neil J.R. 1986 (Eds.). Stable Isotopes in High-Temperature Geological Processes. Rev. Mineral., 16, 570p.

Manuscrito A-1446

Recebido em 20 de junho de 2003

Revisão dos autores em 28 de março de 2005 Revisão aceita em 15 de abril de 2005 